\title{
Structural and Electrochemical Properties of NDND Films Grown in a HFCVD System
}

Adriana F. Azevedo, Mauricio R. Baldan and Neidenei G. Ferreira

ECS Trans. 2012, Volume 43, Issue 1, Pages 203-209. doi: $10.1149 / 1.4704959$

Email alerting Receive free email alerts when new articles cite this article - sign up in the service box at the top right corner of the article or click here 


\title{
Structural and Electrochemical Properties of NDND Films Grown in a HFCVD System
}

\author{
A.F. Azevedo, M.R. Baldan and N.G. Ferreira \\ Instituto Nacional de Pesquisas Espaciais, SJCampos, São Paulo, 12227-010, Brazil
}

\begin{abstract}
Nitrogenated nanocrystalline diamond films were grown from hot filament reactor in $\mathrm{CH}_{4}-\mathrm{Ar}-\mathrm{H}_{2}-\mathrm{N}_{2}$ gas mixtures. They were characterized using scanning electronic microscopy and Raman spectroscopy. Significant changes on the film surface morphologies and Raman spectra were observed due to $\mathrm{N}_{2}$ addition. Their electrochemical properties were studied by cyclic voltammetry. The electrodes behavior showed to be controlled by the degree on nitrogenation. With the increase of the nitrogen content in the reaction gas mixture (from 2 to $20 \mathrm{vol} \%$ ), the reversibility of reactions in the $\mathrm{Fe}(\mathrm{CN})_{6}{ }^{3-/ 4}$ redox system in the films increased. In respect of the electrodes grown in experimental conditions described in this work, they have the properties very close to those grown in microwave plasma reactor.
\end{abstract}

\section{Introduction}

The nanocrystalline diamond (NCD) films are composite structures of diamond nanocrystals and amorphous non-diamond matrix. They have meritorious nature in both mechanical and electrical properties [1-2]. Doping of NCD films further promotes their performance and makes them more suitable for practical applications. Nitrogen is among a few suitable dopants for NCD and forms deep donors as a n-type dopant. The addition of nitrogen on structure of diamond films has a profound impact on the conductivity, field emission and electrochemical behavior [3]. These properties of NDND (nitrogen doped nanocrystalline diamond) films depend largely upon the amount, composition, and bonding properties of non-diamond phases [3]. For instance, molecular-dynamics simulation had shown that the grain boundary sites are more preferable for incorporation of nitrogen atoms than the diamond bulk [4]. Thus, the nitrogen atom effect on the conductivity is indirect, being more related to structural changes than that in the real doping [5]. These structural changes occur because the incorporation of nitrogen forms the larger clustering and disordering of graphite-like $\mathrm{sp}^{2}$-bonded carbons [6].

Frequently, most of the NDND films have been obtained by microwave plasma reactor with gas mixture of $\mathrm{CH}_{4}, \mathrm{~N}_{2}$ and $\mathrm{Ar}$ [1,3,7-12] or $\mathrm{CH}_{4}, \mathrm{~N}_{2}, \mathrm{H}_{2}$ and $\mathrm{Ar}[2,5,13]$ and electrical arc plasma $\left(\mathrm{CH}_{4} / \mathrm{N}_{2} / \mathrm{H}_{2} / \mathrm{Ar}\right)$ [14]. To the best of our knowledge, the use of hot filament reactor is reported only by Haubner et al. [15] and Kshirsagar et al. [16] using $\mathrm{CH}_{4} / \mathrm{N}_{2} / \mathrm{H}_{2}$. Haubner et al. [15] have compared the influences of phosphorous, nitrogen and boron additions on the growth mechanism of diamond films. They have concluded that low nitrogen addition $\left(<\mathrm{N}_{2} / \mathrm{CH}_{4}=0.8\right)$ causes the formation of $\mathrm{HCN}$ or $\mathrm{CN}$ during diamond deposition. The formation of these compounds can decrease the carbon saturation in the system and thus improves diamond quality. $\mathrm{CN}$ radicals can also take the 
role of atomic hydrogen and help stabilize the diamond surface by preferential etching. However, the diamond growth rate reaches a maximum with increasing nitrogen addition and after this point a further reduction. Kshirsagar et al. [16] have studied the evolution of diamond films morphology grown as a function of $\mathrm{N}_{2}$ additions. They have observed a morphological transition from [111] to [100] faceted crystals with increase of nitrogen concentration but the threshold nitrogen concentration required depends on the $\mathrm{CH}_{4}$ gas concentration. From their results, they concluded that nitrogen might have behaved as a catalyst in the growth of diamond films.

Considering the electrochemical applications of these electrodes, Chen et al. [17] and Pleskov et al. [2,5,14] reported interesting results, but they used microwave reactor for their experiments. Therefore, the subject of this work is to obtain NDND films on a silicon substrate with different concentrations of $\mathrm{N}_{2}$ in $\mathrm{CH}_{4}+\mathrm{H}_{2}+\mathrm{Ar}$ gas by using a HFCVD system to electrochemical applications. We decide to keep this composition $\left(\mathrm{CH}_{4} / \mathrm{H}_{2} / \mathrm{Ar}\right)$ because it is the same used by us on the deposition of boron doped nanocrystalline diamond (BDND) and we are getting excellent results with this experimental condition [18]. The use of this gas composition in association with hot filament reactor is the novelty of the present work.

\section{Experimental}

Diamond films depositions were performed using hot filament chemical vapor deposition (HFCVD) technique using the following growth parameters: temperature of the $775 \mathrm{~K}$, pressure of the $4 \mathrm{kPa}$ and deposition time of the $5 \mathrm{~h}$. The $\mathrm{CH}_{4}$ and $\mathrm{H}_{2}$ concentrations ( 2 and 6 vol.\%, respectively) were kept constant and $\mathrm{N}_{2}$ concentration varied from 2 to 20 vol. $\%$ in the total gas flux was $200 \mathrm{sccm}$. This allowed $\left[\mathrm{N}_{2}\right] /\left[\mathrm{CH}_{4}\right]$ ratio variation from 1 to 10 . From the gas flow of $200 \mathrm{sccm}$, the Ar was replaced by $\mathrm{N}_{2}$ in the source gas so that $[\mathrm{Ar}]=184-\left[\mathrm{N}_{2}\right]$, where $\left[\mathrm{N}_{2}\right]$ proportion was varied from 4, 20 and $40 \mathrm{sccm}$. The gas composition used to grow the films is shown in the Table I.

\begin{tabular}{|c|c|c|c|c|c|}
\hline \multicolumn{6}{|c|}{ TABLE I. Deposition parameters } \\
\hline $\begin{array}{c}\mathbf{C H}_{\mathbf{4}} \\
{[\mathbf{s c c m}]}\end{array}$ & $\begin{array}{c}\mathbf{H}_{\mathbf{2}} \\
{[\mathbf{s c c m}]}\end{array}$ & $\begin{array}{c}\mathbf{N}_{\mathbf{2}} \\
{[\mathbf{s c c m}]}\end{array}$ & $\begin{array}{c}\mathbf{A r} \\
{[\mathbf{s c c m}]}\end{array}$ & $\begin{array}{c}\mathbf{N}_{\mathbf{2}} / \mathbf{C H}_{\mathbf{4}} \\
{[\mathbf{s c c m}]}\end{array}$ & $\begin{array}{c}\mathbf{N}_{\mathbf{2}} / \mathbf{H}_{\mathbf{2}} \\
{[\mathbf{s c c m}]}\end{array}$ \\
\hline 4 & 12 & 4 & 180 & 1 & 0.3 \\
\hline 4 & 12 & 20 & 164 & 5 & 1.66 \\
\hline 4 & 12 & 40 & 144 & 10 & 3.33 \\
\hline
\end{tabular}

All the films were grown on polished silicon [100] $1 \mathrm{x} 1 \mathrm{~cm}^{2}$ substrates. These substrates were prepared by ultrasonic hexane bath with $0.25 \mu \mathrm{m}$ diamond powder during 60 min. The NDND films were investigated by scanning electron microscopy (SEM) using a JEOL JSM-5310 model and by micro-Raman scattering spectroscopy (Renishaw microscope system 2000) using the $514.5 \mathrm{~nm}$ line of an argon ion laser taking the spectra covering the range from 1000 to $2000 \mathrm{~cm}^{-1}$. Electrochemical measurements were carried out using Autolab PGSTAT 302 equipment in a three-electrode compartment cell with $50 \mathrm{~cm}^{3}$ of capacity. The NDND films were used as working electrode and their geometric area in contact with the electrolyte was $0.10 \mathrm{~cm}^{2}$. The platinum coil and $\mathrm{Ag} / \mathrm{AgCl}$ 
electrodes were used as counter and reference electrodes, respectively. The sweep rate of $0.1 \mathrm{~V} \mathrm{~s}^{-1}$ and electrolyte support of $0.5 \mathrm{~mol} \mathrm{~L}^{-1} \mathrm{H}_{2} \mathrm{SO}_{4}$ were used in all measurements. The potential window and reversibility of films were studied by cyclic voltammetry $(\mathrm{CV})$. Before each measurement, the solution was deoxygenated with $\mathrm{N}_{2}$ gas for at least 20 min. All experiment was carried out at room temperature.

\section{Results and Discussions}

The surface morphology of the diamond films grown with the addition of $\mathrm{N}_{2}$, i.e, $1<$ $\left[\mathrm{N}_{2}\right] /\left[\mathrm{CH}_{4}\right]<10$, are shown in the Figs. $1 \mathrm{a}, 1 \mathrm{~b}$ and $1 \mathrm{c}$. SEM images permitted detailed observation of the cluster formations as a function of the $\mathrm{N}_{2}$ increased in feed gas. The morphologies of films varied from a uniform morphology and flat surface $\left[\mathrm{N}_{2}\right] /\left[\mathrm{CH}_{4}\right]=1$ ( 2 vol.\%) to clusters with different sizes $\left[\mathrm{N}_{2}\right] /\left[\mathrm{CH}_{4}\right]=5$ (10 vol.\%), followed by complete coalescence and decrease of these clusters $\left[\mathrm{N}_{2}\right] /\left[\mathrm{CH}_{4}\right]=10(20 \mathrm{vol} . \%)$. Similar behavior was observed by Haubner et al. [15], where the morphology changed from faceted to ballas-like as the nitrogen addition were incorporated in films.
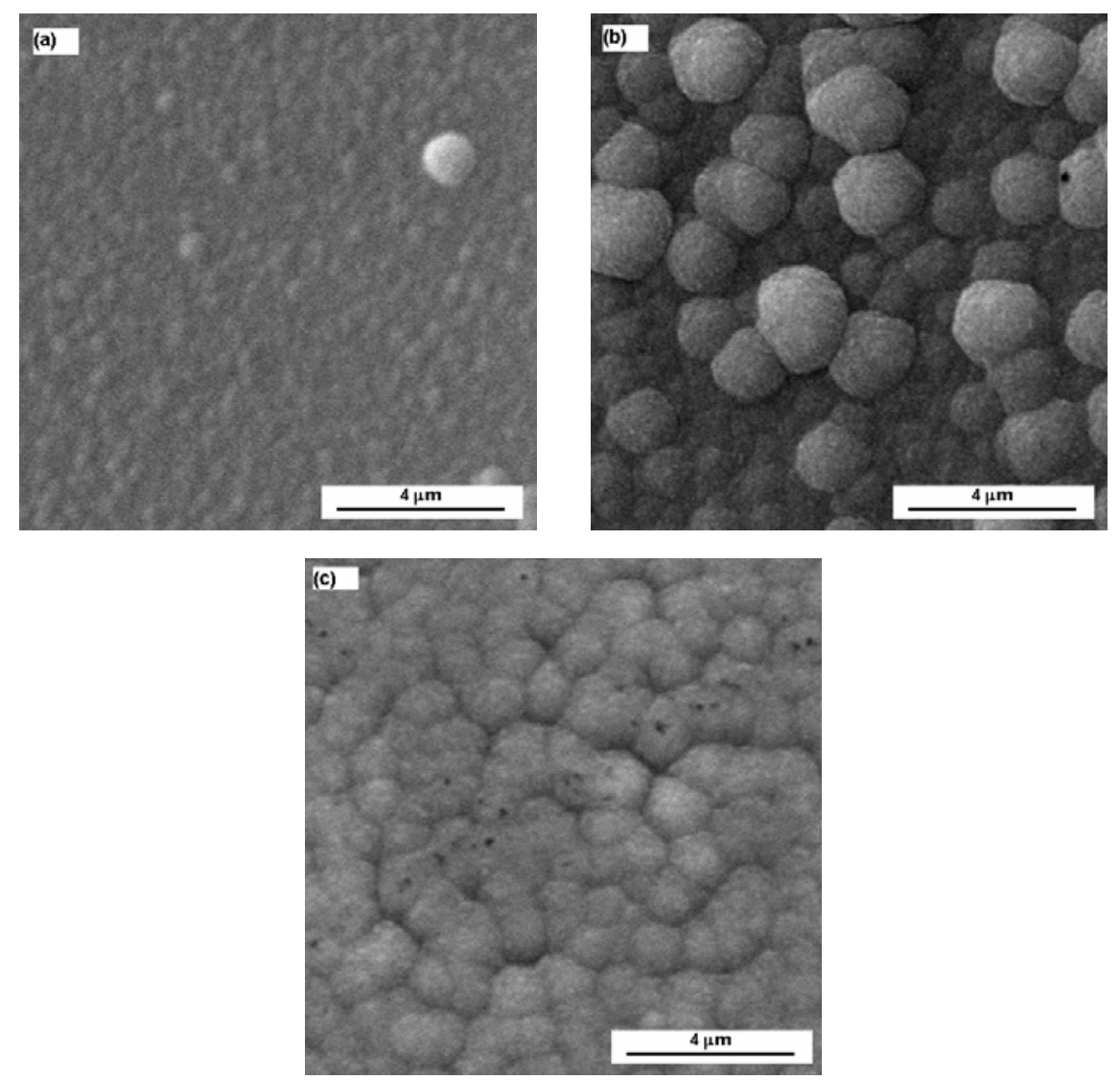

Figure 1. SEM topographic images of the NDND films grown with (a) 2, (b) 10 and (b) 20 vol. $\%$ of $\mathrm{N}_{2}$, respectively. 
The literature reports that the increase of nitrogen concentration in feed gas favors the decrease of grain size, regardless of the gas mixture or reactor used $[8,16]$, and increases the concentration of lattice defects, as well as, the relative content of $\mathrm{sp}^{2}$-hybridized carbon phase [5]. Besides, it is also known that the reduction of the methane flow rate decreases the growth source and increases the diamond nucleation. It is important to emphasize that these films are characterized by the increasing of nucleation density. Therefore, at high density the nanosized diamond grains gather together to form a conglomerate leading to cauliflower clusters. For nitrogen addition from $\left[\mathrm{N}_{2}\right] /\left[\mathrm{CH}_{4}\right]=1$ to $\left[\mathrm{N}_{2}\right] /\left[\mathrm{CH}_{4}\right]=10$ reveled the changes in the morphology from flat surface to isolated islands. Apparently, upon introducing nitrogen into NCD films, the most energetically favorable sites should be at grain boundaries, where the lone pair electrons in nitrogen can facilitate the transformation of tetrahedral coordinated sites of $\mathrm{sp}^{3}$-like carbon configuration into three-fold-coordinated sites of $\mathrm{sp}^{2}$-like carbon arrangement with a perturbed $\mathrm{N}$-doped characteristic at grain boundaries [6].

The first order Raman spectra for these films peaks are depicted in Fig. 2. This figure also shows four deconvoluted peaks. The contribution of the diamond peak at about 1332 $\mathrm{cm}^{-1}$ in visible Raman spectra of NCD films is not clear due to overlapping of the D $\left(1345 \mathrm{~cm}^{-1}\right)$ band, which is more sensitive to non-diamond phases. The spectra also exhibited two shoulders at 1150 and $1490 \mathrm{~cm}^{-1}$ related to transpolyacetylene (TPA) segments at the grain boundaries of NCD surface [19]. The Raman spectra in the frequency range $1550-1600 \mathrm{~cm}^{-1}$ ( $\mathrm{G}$ band) is correlated to the vibrations of the $\mathrm{sp}^{2}$ bonded graphitic carbon. With the increasing of the nitrogen content, we may observe that the $\mathrm{G}$ band shifted to lower frequency and broaden. This broader peak may indicate that the diamond nanograins are surrounded by a considerable amount of graphitic grains. According to Kshirsagar et al. [16] this behavior is related to the graphite crystallite size or its conversion into amorphous carbon.

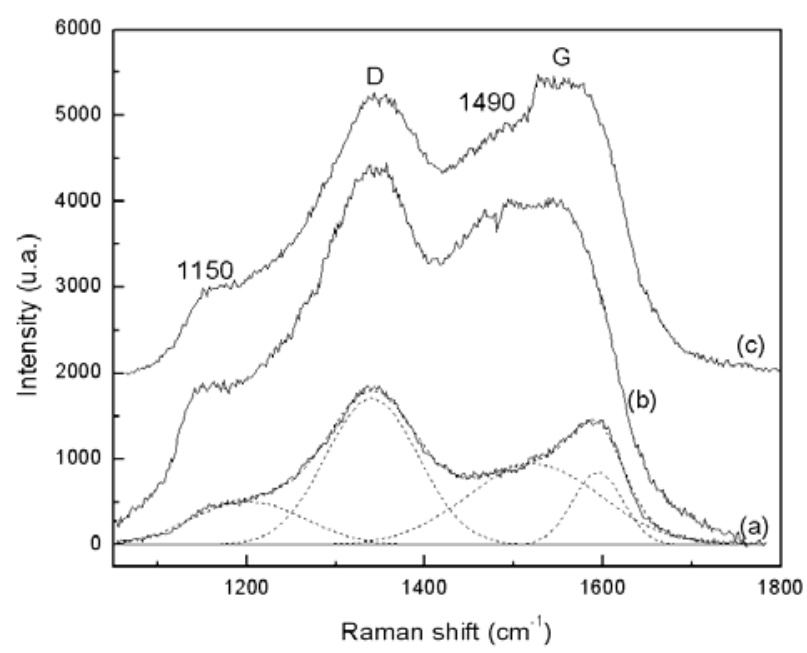

Figure 2. Raman spectra of NDND films grown with (a) $2 \%$; (b) $10 \%$ and (c) $20 \%$ of $\mathrm{N}_{2}$.

Cyclic voltammetry i-E curves are useful to exam the diamond film behavior because the electrochemical response is highly sensitive to physicochemical properties of the 
electrode. The magnitude of the background current and the voltammetric features present within the working potential window are sensitive to nondiamond $\mathrm{sp}^{2}$ carbon impurity presence [20]. Fig.3 shows cyclic voltammetry i-E curves for the NDND films in $0.5 \mathrm{~mol} \mathrm{~L}^{-1} \mathrm{H}_{2} \mathrm{SO}_{4}$ solution. These films have a low capacitive current with a background around $5 \mathrm{a} 13 \mu \mathrm{Acm}^{-2}$ and the potential window $\sim 2.0 \mathrm{~V} v s$. $\mathrm{Ag} / \mathrm{AgCl}$ independent of $\mathrm{N}_{2}$ doping level. This value is similar to those described in the literature [5]. Moreover, the electrode grown with 20 vol.\% showed a pronounced anodic peak on the forward sweep at $1.5 \mathrm{~V}$ vs. $\mathrm{Ag} / \mathrm{AgCl}$. This oxidation process is assigned to the oxidation of the grain-boundary $\mathrm{sp}^{2}$ carbon present on the diamond surface [20]. In fact, as observed in SEM image and Raman spectrum, this film has the smallest grain sizes and in consequence a large amount of grain boundaries containing $\mathrm{sp}^{2}$-hybridized carbon phase than that for electrodes grown with 2 and $10 \%$ of $\mathrm{N}_{2}$, justifying this result.

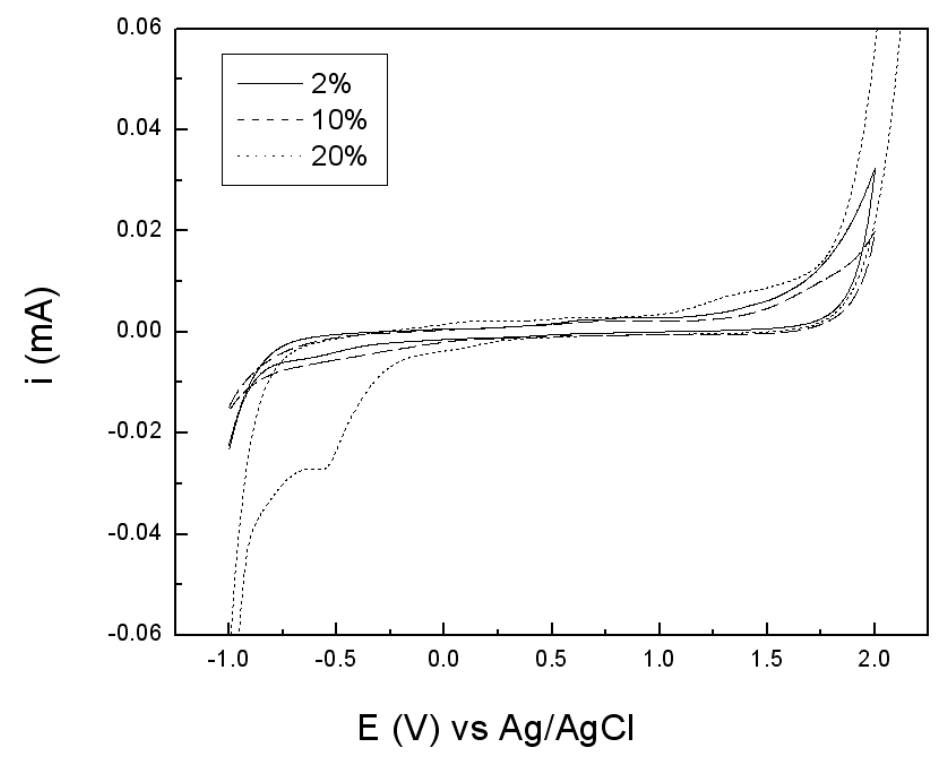

Figure 3. Cyclic voltammetry i-E curves for in $0.5 \mathrm{~mol} \mathrm{~L}^{-1} \mathrm{H}_{2} \mathrm{SO}_{4}$ at NDND films. Scan rate at $0.1 \mathrm{~V} \mathrm{~s}^{-1}$.

In order to characterize the electrochemical kinetic we have applied cyclic voltammetry using the redox couple $\mathrm{Fe}(\mathrm{CN})_{6}^{3-/ 4-}$. This redox system includes reactions that depend on the specific interactions with the surface electrode. Besides, the electrode kinetics for this kind of redox couple tends to be more sensitive to the surface functionalities on $\mathrm{sp}^{2}$-bonded carbon electrodes [21]. The electrode grown with 2 vol.\% $\mathrm{N}_{2}$ has an irreversible behavior, while the values of $\Delta \mathrm{E}_{\mathrm{p}}$ varied from 140 to $70 \mathrm{mV}$ as the concentration of $\mathrm{N}_{2}$ increased from 10 to 20 vol.\% as shown in Fig.4. For reference, the theoretical $\Delta \mathrm{E}_{\mathrm{p}}$ for a kinetically-fast redox system is $59 / \mathrm{n} \mathrm{mV}$ for $\mathrm{Fe}(\mathrm{CN})_{6}^{3-/ 4-}\left(1 \mathrm{e}^{-}\right.$redox reaction). This indicate that the film grown with 20 vol.\% $\mathrm{N}_{2}$ possess the requisite surface structure, chemical composition, and electronic properties to support rapid electron transfer for this particular redox system. 


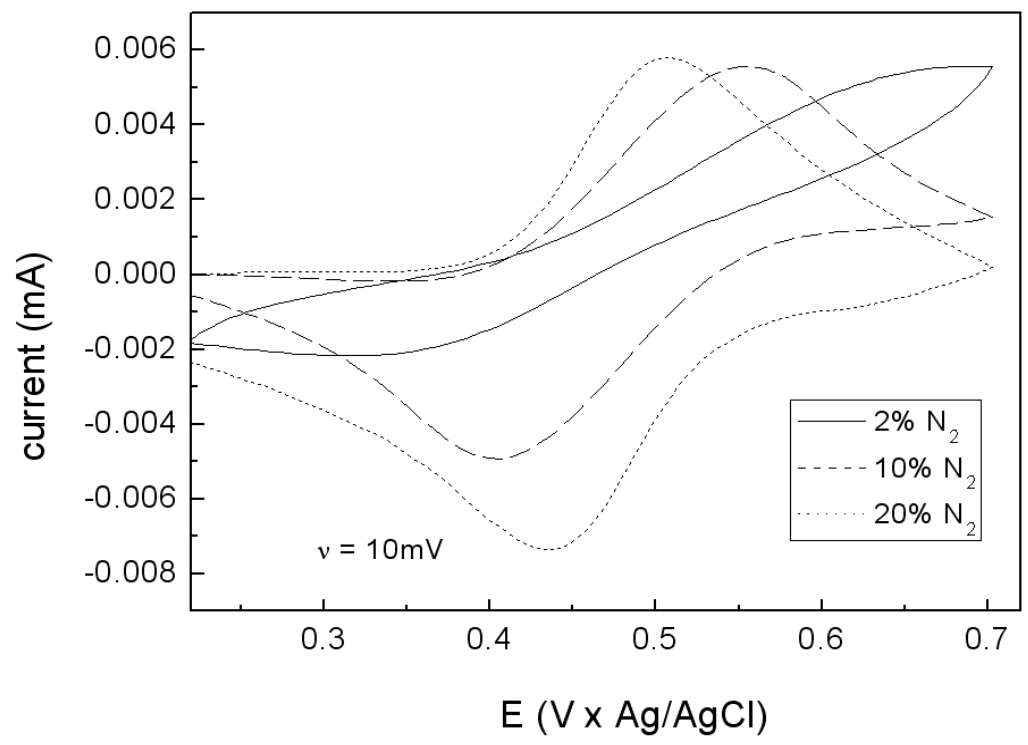

Figure 4. Cyclic voltammetry i-E curves for in $1 \mathrm{mmol} \mathrm{L}^{-1} \mathrm{~K}_{4} \mathrm{Fe}(\mathrm{CN})_{6}{ }^{3-4-}+0.5 \mathrm{~mol} \mathrm{~L}^{-1}$ $\mathrm{H}_{2} \mathrm{SO}_{4}$ at NDND films. Scan rate at $0.1 \mathrm{~V} \mathrm{~s}^{-1}$.

\section{Conclusions}

The effect of the nitrogenation on the morphology, structural and electrochemical properties of the NCD films were evaluated. From SEM images, the morphologies were quite different for all NDND films as a function of $\mathrm{N}_{2}$ addition. The analysis of Raman spectra showed that the $G$ peak intensity became too meaningful in relation to D peaks as the nitrogen concentration increase in films indicating a high proportion of $\mathrm{sp}^{2}$-bonded carbon in the film grown with $20 \mathrm{vol} . \%$ of $\mathrm{N}_{2}$. The concentration of $\mathrm{N}_{2}$ in the reaction gas equal to 20 vol.\% allows obtaining electrodes with metal-like properties, which demonstrate reversible behavior in the $\mathrm{Fe}(\mathrm{CN})_{6}{ }^{3-/ 4-}$ redox couple solutions. Because of good electrochemical response and stability of structural characteristics, the NDND is a promising electrode material.

\section{Acknowledgments}

Special thanks to FAPESP, CAPES and CNPq for financial support and Mrs. Maria Lúcia Brison by the SEM analyses.

\section{References}

1. K. Teii and, T. Ikeda, Diam. Relat. Mater, 16, 753 (2007).

2. Y.V. Pleskov, M.D. Krotova, V.G. Ralchenko, A.V. Saveliev and A.D. Bozhko, Russian J. Electrochem. Soc., 43, 827 (2007). 
3. J. Birrel, O. Auciello, J.M. Gibson, D.M. Gruen and J.A. Carlisle, Appl. Phys. Lett., 81, 2235 (2002).

4. P. Zapol, M. Sternberg, L.A. Curtis, T. Frauenheim and D.M. Gruen, Phys. Rev. B., 65, 045403 (2002).

5. Y.V. Pleskov, M.D. Krotova, V.V. Elkin, V.G. Ralchenko, A.V. Saveliev, S.M. Pimenov and P.Y. Lim, Electrochim. Acta., 52, 5470 (2007).

6. C.-C. Teng, S.-M. Song, C.-M. Sung and C.-T. Lin, J. Nanomater., 2009, 1 (2009).

7. J. Birrel, J.E. Gerbi, O. Auciello, J.M. Gibson, D.M. Gruen and J.A. Carlisle, J. Appl. Phys., 93, 5606 (2003).

8. Y.K. Liu, P.L. Tso, D. Pradhan, I.N. Lin, M. Clark and Y. Tzeng, Diamond Relat. Mater., 14, 2059 (2005).

9. S. Bhattacharyya, O. Auciello, J. Birrel, J.A. Carlisle, L.A. Curtiss, A.N. Goyette, D.M. Gruen, A.R. Krauss, J. Schlueter, A. Sumant and P. Zapol, Appl. Phys. Lett., 79, 1441 (2001).

10. K. Subramanian, W.P. Kang, J.L. Davidson and W.H. Hofmeister, J. Vac. Sci. Technol. B, 23, 786 (2005).

11. S.A. Rakha, G. Yu, J. Cao, S. He and X. Zhou, J. Appl. Phys., 107, 114324 (2010).

12. R. Arenal, G. Montagnac, P. Bruno and D.M. Gruen, Phys. Rev. B., 76, 245316 (2007).

13. I.I. Vlasov, V.G. Ralchenko, E. Goovaerts, A.V. Saveliev and M.V. Kanzyuba, Phys. Stat. Sol. A., 203, 3028 (2006).

14. Y.V. Pleskov, M.D. Krotova, V.G. Ralchenko, I.I. Vlasov and A.V. Saveliev, Russian J. Electrochem., 46, 1063 (2010).

15. R. Haubner, S. Bohr and B. Lux, Diam. Relat. Mater., 8, 171 (1999).

16. S.T. Kshirsagar, R.B. Kshirsagar, P.S. Patil, A.V. Kulkarni, A.B. Mandale, A.B. Gaikwad and S.P. Gokhale, Diam. Relat. Mater., 14, 232 (2005).

17. Q. Chen, D.M. Gruen, A.R. Krauss, T.D. Corrigan, M. Witek and G.M. Swain, J. Electrochem. Soc., 148, E44 (2001).

18. A.F. Azevedo, N.A. Braga, F.A. Souza, J.T. Matsushima, M.R. Baldan and N.G. Ferreira, Diam. Relat. Mater., 19, 462 (2010).

19. A.C. Ferrari and J. Robertson, Philos. Trans. R. Soc. Lond. A, 362, 2477 (2004).

20. A.E. Fischer, Y. Show and G.M. Swain, Anal. Chem., 76, 2553 (2004).

21. P. Chen and R.L. McCreery, Anal. Chem., 68, 3958 (1996). 